\title{
EXCLUSÃO E DIFERENÇA NAS POLÍTICAS PÚBLICAS DE RADIODIFUSÃ̃ COMUNITÁRIA \\ NO BRASIL: \\ POSSIBILIDADES E LIMITES A PARTIR DO PENSAMENTO DE JÜRGEN HABERMAS
}

Daniel Augusto Vila-Nova Gomes*

\section{Exclusão nas políticas públicas de radiodifusão comunitária no Brasil}

Como uma onda no $\mathrm{ar}^{1}$, ecoam vozes que clamam por políticas públicas mais legítimas para a regulação das rádios comunitárias no Brasil. Na prática, a grande maioria dos pedidos de autorização para a exploração desse serviço de inegável relevância pública é arquivada ou obstada por trâmites administrativos perante o Ministério das Comunicações (MINICOM), os quais chegam a durar até 8 anos. ${ }^{2}$

No dia 1 으 de dezembro de 2005, realizou-se audiência pública para discutir os rumos da legislação de regência dessa modalidade de radiodifusão. Nessa oportunidade, além do lançamento de perspectivas para o futuro da radiodifusão comunitária, o debate público norteou-se pela necessidade de um novo marco regulatório. Tratou-se, portanto, de uma reflexão que a comunidade política brasileira tem realizado para estabelecer diretrizes adequadas para a implementação de políticas públicas no âmbito da comunicação como um direito humano. ${ }^{3}$

\footnotetext{
"Bacharel em Direito pela Universidade de Brasília-UnB; Mestrando em "Direito, Estado e Constituição" no Programa de Mestrado da Faculdade de Direito da Universidade de Brasília (FD/UnB) na Linha de Pesquisa Políticas Públicas e Democracia; Professor nas disciplinas Noções de Direito, Introdução ao Direito I e Teoria Geral do Direito Público na UnB, no período compreendido entre setembro de 2005 e julho de 2006; Pesquisador do Grupo de Pesquisa Sociedade, Tempo e Direito; Membro do Grupo de Estudos em Direito das Telecomunicações - GETEL/UnB; e Assessor Jurídico do Ministro Gilmar Ferreira Mendes no Supremo Tribunal Federal (STF).

${ }^{1}$ Menção ao filme Uma Onda no Ar, lançado em 2002, dirigido por Helvécio Ratton e inspirado na experiência de operação e regularização da Rádio Favela de Belo Horizonte. A rádio começou a operar em 1981 por iniciativa do cidadão/fundador Misael Avelino dos Santos.

2 Para um interessante levantamento desses estudos, cf. Lopes, Cristiano Aguiar. Política pública de radiodifusão comunitária no Brasil: exclusão como estratégia de contra-reforma. Dissertação de mestrado apresentada para a obtenção do título de Mestre na Faculdade de Comunicação da Universidade de Brasília. Orientador: Professor Dr. Murilo César Ramos. Abril, 2005.

${ }^{3}$ As expressões utilizadas em itálico, neste parágrafo, fazem referência direta a alguns dos temas discutidos nos

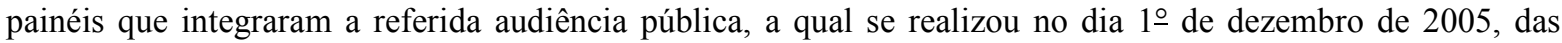
10:00h às 20:30h, com a organização das seguintes comissões parlamentares da Câmara dos Deputados: a Comissão de Direitos Humanos e Minorias; e a Comissão de Legislação Participativa. 
Recente reportagem da Carta Capital, datada de 09 de agosto de 2006, denuncia experiências e dificuldades comuns às rádios comunitárias do país. Entre a clandestinidade e a perda de identidade decorrente do risco de apropriação indevida por partidos políticos ${ }^{4}$, a discussão sobre os problemas técnicos, burocráticos, criminais e legislativos consiste em primeiro passo para a construção de efetivo controle normativo da sociedade e do Estado brasileiro quanto às políticas públicas destinadas ao setor. Em última instância, este artigo propõe a idéia de controle normativo como uma alternativa teórica que, ancorada na noção habermasiana de esfera pública, busca lidar com o papel desempenhado pelos múltiplos sujeitos envolvidos (Estado, agências, cidadãos, empresas, corporações, permissionários, concessionários, comunidades locais, regionais, nacionais e transnacionais, entidades do terceiro setor etc.) para o controle jurídico do acesso, participação e distribuição dos benefícios individuais, coletivos e sociais relacionados à exploração das atividades de radiodifusão comunitária.

De outro lado, os primeiros estudos nessa área já apontam que pequeno número de grupos religiosos e oligarquias familiares (muitas vezes ligados a atuais exercentes de mandatos parlamentares) são detentores da grande maioria das concessões e autorizações relativas aos meios de comunicação de massa. Para Célia Stadnick, esse fenômeno de exclusão poderia ser denominado "coronelismo eletrônico". 5

Embora as primeiras experiências da radiodifusão comunitária brasileira possam ser identificadas desde 1970, as rádios comunitárias apenas se organizaram politicamente durante a década de 1990. O "movimento das rádios comunitárias"6 passou a pautar- se por uma política de inclusão e deliberação de medidas mais democráticas. Somente a partir de

\footnotetext{
${ }^{4}$ Nesse particular, é válido transcrever o seguinte trecho da reportagem: "Israel Bayma, pesquisador do Laboratório de Políticas de Comunicação da Universidade de Brasília, tem um estudo, ainda inédito, sobre radiodifusão. Nele, a partir de uma amostra de 820 pedidos de licença para rádios comunitárias em 2002, o especialista em telecomunicações constatou que $87 \%$ não correspondiam a emissoras efetivamente comunitárias apesar de se apresentarem como tal. No mesmo ano, prossegue Bayma representantes de emissoras tidas como comunitárias, já com concessão, doaram 256.156 reais para políticos em campanha. O PMDB recebeu $14,5 \%$ desse total, o PMN ficou com 14,28\% e o PSDV com 12,42\%. Já nas eleições de 2004, as entidades de rádios comunitárias contribuíram com 879.750 reais para os partidos políticos, e o PPS recebeu $34,12 \%$ desse valor. Bayma comenta: - Isso não é tecnicamente ilegal, mas demonstra que há interesse político das entidades que representam essas rádios." ATHAYDE, Pydia de. Na onda da política. Carta Capital, São Paulo, n. 405, p. 30-31.

${ }^{5}$ STADNICK, Célia A. A hipótese do fenômeno do Coronelismo Eletrônico e as ligações dos parlamentares federais e governadores com os meios de comunicação de massa no Brasil. Porto Alegre, Pontifícia Universidade Católica do Rio Grande do Sul (PUC-RS), 1991. Mimeo.

${ }^{6}$ Nesse sentido, é válido mencionar alguns movimentos, tais como: o Fórum Nacional para a Democratização das Comunicações (FNDC), a Associação Brasileira de Radiodifusão Comunitária (Abraço), a Associação Mundial das Rádios Comunitárias - sub-região Brasil (Amarc-Brasil), a Rede Brasil de Comunicação Cidadã (RBC) etc.

PRISMAS: Dir., Pol.Pub. e Mundial., Brasília, v.3, n, 2, p. 256-277, jul/dez.2006 
então, tornou-se possível falar em uma espécie de "reforma agrária do ar"7 - uma pauta de reivindicações que, para não se tornar obsoleta, precisa de urgente adaptação aos efeitos da convergência tecnológica das comunicações e da adoção de novo padrão digital para o rádio e a televisão.

Nesse cenário de exclusão, inúmeras críticas têm sido realizadas desde a edição da Lei no 9.612/1998, a qual instituiu o serviço de radiodifusão comunitária no Brasil ${ }^{8}$. O objetivo dessa legislação era atender o grande número de pedidos de autorização formulados ao MiniCOM para a implantação de emissoras de baixa potência. A partir desse marco legal, fundava-se um regime de autorizações de reduzida área de cobertura para o atendimento de comunidades envolvidas no planejamento e na transmissão de programas que fossem de seu interesse. A lei não permite, ademais, que a entidade ou a comunidade autorizada para a exploração dessa modalidade de atividade radiodifusora obtenha quaisquer fins lucrativos.

Como se percebe, porém, os resultados alcançados por esse modelo de autorização previsto na lei indicam um déficit de legitimidade nas políticas públicas desse setor. Se, de um lado, a burocracia para se obter uma autorização acaba se tornando um atrativo para a ilegalidade, de outro, são inegáveis as influências causadas pela concentração do mercado brasileiro de comunicações. ${ }^{9}$ Para aprofundar os dilemas de implementação de políticas públicas nessa área, é pertinente analisar outro episódio relativo ao processamento de pedido de outorga de autorização para exploração de radiodifusão comunitária.

A Associação das Mulheres de Juazeiro do Norte (AMUJUN) teve seu pedido indeferido pelo Ministério das Comunicações (MINICOM). Nesse caso, a solicitação não foi atendida sob o fundamento de que a AMUJUN promoveria “discriminação sexual". Para embasar essa decisão administrativa, o MINICOM invocou o inciso I, do artigo 4으, da Lei nํㅡ 9.612/1998. Tal dispositivo enuncia, em linhas gerais, que as emissoras atenderão, em sua programação, à diretriz legal da "não discriminação de raça, religião, sexo, preferências sexuais, convicções político-ideológico-partidárias e condição social nas relações

\footnotetext{
7 Tendo em vista que os espectros de radiofreqüência são limitados e se propagam pelo ar atmosférico, o "movimento das rádios comunitárias" pugna pela democratização de seu uso por meio de uma distribuição mais equânime das possibilidades de acesso à radiodifusão. Daí falar-se em "reforma agrária do ar".

${ }^{8}$ Na Exposição de Motivos no 30/1996, do Ministério das Comunicações, apresentada ao Congresso Nacional (Mensagem no 323, de 16 de abril de 1996), o Poder Executivo (Governo de Fernando Henrique Cardoso) já acenava com a necessidade de discussões oficiais acerca da implementação das bases legais para a radiodifusão comunitária no Brasil. Como resultado desse processo legislativo, a Lei no 9.612/1998 instituiu o serviço de radiodifusão comunitária no Brasil.

${ }^{9}$ Em reportagem intitulada: Na onda da política, Phydia de Athayde apresenta levantamentos estatísticos que asseveram que "O processo para liberar uma emissora leva até oito anos." Tal conclusão indica a necessidade de analisar o rigor dos critérios exigidos das rádios comunitárias de modo a possibilitar essa modalidade de prestação de serviços de radiodifusão. ATHAYDE, Pydia de. Na onda da política. Carta Capital, São Paulo, n. 405, p. 30-31. 
comunitárias". A negativa do pedido de autorização da AMUJUN foi determinada, portanto, sob o argumento de que as políticas públicas de radiodifusão comunitária deveriam evitar a promoção de atividade discriminatória. Como resultado, esse processo administrativo foi arquivado em 27 de julho de $2001 .^{10}$

Antes de abordar algumas das imprecisões jurídico-constitucionais que a situação concreta de preterição pode denotar, é necessário reconhecer as rádios comunitárias como espaços autônomos e privilegiados para a construção democrática da cidadania. Destarte, a partir do momento em que uma comunidade tenha possibilidades de exercer legitimamente a atividade, torna-se possível a participação de cada um dos indivíduos na elaboração coletiva da forma e do conteúdo da programação a ser veiculada.

A rigor, essas experiências, quando bem sucedidas, podem constituir verdadeiros instrumentos de problematização de temas envolvidos com a formação da opinião e da vontade política coletivamente vinculante, tais como: a discussão de excessos e déficits nas relações de trabalho, nas campanhas eleitorais, na fiscalização da prestação de serviços públicos e em diversas áreas de formulação de políticas públicas, por exemplo, saúde e educação. Em outras palavras, a radiodifusão comunitária exercita os limites e as possibilidades discursivas daquilo que, segundo Jürgen Habermas, a historiografia e as teorias social e jurídica contemporâneas denominam "esfera pública".

É exatamente nesse contexto de deliberação sobre alternativas para a crescente exclusão promovida pelo atual modelo brasileiro de radiodifusão comunitária que este artigo pretende realizar breves considerações. Assim, com base nas repercussões históricas e sociológicas da evolução da noção de esfera pública no pensamento de Habermas (Seção 1), parece-nos pertinente investigar os limites e possibilidades de emancipação política dessa categoria histórico-social, de considerável repercussão no campo dos direitos, em especial, quanto à liberdade de expressão e à prerrogativa de acesso público aos meios de comunicação de massa.

Para essa análise, o exemplo concreto da AMUJUN é duplamente instigante. Ao mesmo tempo em que permite uma análise das políticas públicas no setor de radiodifusão comunitária no Brasil, a decisão administrativa do MINICOM revela algumas das armadilhas discursivas que, uma vez apropriadas, podem ser utilizadas como impedimento para a inclusão da mulher (das outras cidadãs) nas possibilidades de emancipação política no interior da esfera pública (Seções 2 e 3). A expectativa desta investigação é contribuir para o

\footnotetext{
${ }^{10}$ BRASIL. Ministério das Comunicações. Processo no 5360.01021/99.
} 
reconhecimento de que a questão das políticas públicas destinadas às rádios comunitárias pode envolver, além da luta e da conquista de direitos de liberdade de expressão e igualdade de gêneros, a construção democrática da cidadania e a emancipação política de identidades sociais coletivas.

\section{Cidadania, democracia e esfera pública na obra de Jürgen Habermas}

Ao iniciar a reflexão acerca dos limites e das possibilidades democráticas de emancipação política cidadã, deve-se destacar que a distinção entre esfera pública e esfera privada não é linear no pensamento de Jürgen Habermas. Na primeira formulação dessa diferenciação, a obra Mudança Estrutural na Esfera Pública (1961) ${ }^{11}$ denota a alteração da função política e social da esfera pública burguesa em razão de diversas transformações na estrutura da sociedade, tais como: a polarização da esfera social e da esfera íntima, caracterizada pelo surgimento novas relações familiares e de trabalho; a transição do público pensador de cultura ao público consumidor de cultura, em que passam a prevalecer mídias e públicos de consumo massificado no mercado cultural; a decadência da esfera pública burguesa, marcada eminentemente pelas influências que a substituição do jornalismo crítico pelo manipulativo proporcionou nos processos legislativos e eleitorais. ${ }^{12}$

Cerca de trinta anos após a obra original ${ }^{13}$, os estudos historiográficos posteriores exigiram reformulações nas concepções da obra Mudança Estrutural ${ }^{14}$. Ademais, de acordo com os novos postulados de intersubjetividade lingüística da ação social, Habermas reconheceu que não poderia desenvolver uma Teoria Discursiva sem profundas modificações acerca da complexa relação entre direito, política e moral.

${ }^{11}$ O título original da obra foi Strukturwandel der Öffentlichkeit a qual recebeu tradução para o português somente na década de 1980, cf. HABERMAS, J. Mudança Estrutural da Esfera Pública: investigações quanto a uma categoria da sociedade burguesa. Tradução de Flávio R. Kothe. Rio de Janeiro: Tempo Brasileiro, 1984.

${ }^{12}$ HABERMAS, Jürgen Mudança Estrutural da Esfera Pública: investigações quanto a uma categoria da sociedade burguesa. Tradução de Flávio R. Kothe. Rio de Janeiro: Tempo Brasileiro, 1984. (1984:180-259).

13 A respeito das transformações ocorridas na obra habermasiana quanto à noção de "esfera pública" (öffentlichkeit), cf. CALHOUN, Craig (Ed.). Habermas and the public sphere. (Studies in contemporary German social thought). Massachussets Institute of Technology, 1992.

14 Para inúmeras ressalvas historiográficas à obra Mudança Estrutural, cf. DARNTON, Robert. Os dentes falsos de George Washington:Um guia não convencional para o século XVIII. Tradução de José Geraldo Couto. São Paulo: Companhia das Letras, 2005; LA VOPA, Anthony J. Conceiving a Public: Ideas and Society in the Eighteenth-Century Europe. In: The Journal of Modern History. Março: 1992; 64, 1. Academic Research Library. p. 79-116; MAH, Harold. Phantasies of the Public Sphere: Rethinking the Habermas of Historians. In: The Journal of Modern History; Mar. 2000, 72, 1; Academic Research Library, p. 153-182. 
No artigo Further Reflexions on the Public Sphere (publicado em 1992) ${ }^{15}$, a esfera pública foi redefinida ${ }^{16}$, para abranger as condições comunicativas necessárias à formação discursiva da opinião e da vontade do público de cidadãos, ${ }^{17}$ de tal modo que, na obra Faticidade e validade, Habermas afirma que:

A esfera pública pode ser descrita como uma rede adequada para a comunicação de conteúdos, tomadas de posição e opiniões; nela os fluxos comunicacionais são filtrados e sintetizados a ponto de se condensarem em opiniões públicas enfeixadas em temas específicos ${ }^{18}$.

Nota-se, portanto, que, ao contrário da feição eminentemente descritiva de elementos empíricos e contingentes típicos da mudança estrutural de uma sociedade histórica e sociologicamente situada, a sociedade burguesa, o viés normativo da teoria discursiva pressupõe profunda reconstrução das noções de esfera pública e esfera privada em sociedades complexas, plurais e multiculturais. Essa nova abordagem habermasiana de esfera pública renasce, então, em um contexto secularizado, transcendente à tradição originalmente burguesa e coordenado por procedimentos discursivos moralmente fundamentados. Ademais, Habermas parte da idealização de que o espaço público estaria assentado em pressupostos culturais, estruturais e morais discursivamente institucionalizados pelos procedimentos requeridos para a garantia das inúmeras condições de validade para a promoção de um debate democrático. ${ }^{19}$ Essa é uma reflexão que pode e deve ser confrontada com o problema das políticas públicas invocáveis como coletivamente vinculantes no contexto da radiodifusão, por exemplo.

Sob a proposta cidadã desse modelo deliberativo de democracia, as discussões estão sempre abertas, em princípio, às críticas e à participação inclusiva dos múltiplos atores sociais potencialmente envolvidos. Além disso, para que os meios normativos de circulação de poder e formação de vontade estejam racionalmente ancorados nos elementos normativos de sua legitimação discursiva, é necessária a participação dos cidadãos e das cidadãs em um

\footnotetext{
${ }^{15}$ HABERMAS, Jürgen. Further reflections on the Public Sphere e Concluding Remarks. Translated by Thomas Burger In: CALHOUN, Craig (Ed.). Habermas and the public sphere. (Studies in contemporary German social thought). Massachussets Institute of Technology, 1992 Craig, Calhoun (Ed.), 1992. pp. 421-461.

16 Um caso sintomático dessa redefinição pode ser visualizado a partir da concepção um tanto quanto "pessimista", segundo o próprio Habermas, na obra Mudança Estrutural (datada de 1961). Em Further Reflections on the Public Sphere (datada de 1992), Habermas chega a ressalvar, inclusive, uma espécie de ambivalência do papel exercido pelos meios de comunicação de massa na contemporaneidade, o qual pode ocupar, inclusive, um papel "positivo". Nesse contexto, as revoluções democráticas do leste europeu foram consideravelmente alavancadas pela ampla cobertura televisiva da "queda do muro de Berlim", ocorrida em 1989.

${ }^{17}$ Habermas (1992:446).

${ }^{18}$ Habermas (1997b:92 - realces no original).

19 Acerca das barreiras e idealizações da constituição discursiva das noções de "esfera pública" e "sociedade civil”, $c f$. Habermas (1997b:106-121).

PRISMAS: Dir., Pol.Pub. e Mundial., Brasília, v.3, n, 2, p. 256-277, jul/dez.2006 
contínuo processo reflexivo de reconstrução racional.

As esferas pública e privada, por fim, relacionam-se à dimensão de direito enquanto medium de generalização de expectativas normativas na sociedade e de mediação social entre faticidade e validade. Segundo essa perspectiva, para lidar com os riscos de legitimação nas sociedades atuais, o direito deve promover a garantia das condições discursivas necessárias para o surgimento de interações comunicativas mediadas normativamente e imunes à violência ${ }^{20}$. Daí tratar-se de uma amplitude de legitimação jurídica, discursivamente estruturada no ambiente social, para a análise da circulação institucional do poder político administrativo mediado pelo direito.

De outra parte, a esfera privada poderia ser concebida, grosso modo, como âmbito de interação pública em que seria possível certa liberdade ou autonomia para o exercício de questões que estejam historicamente relegadas no âmbito da autonomia privada, tais como, os exemplos relativos a assuntos dependentes das liberdades individuais de consciência, crença, opinião, pensamento, associação, intimidade e identidade. ${ }^{21} \mathrm{O}$ que se pretende destacar é o potencial compreensivo que esses recursos teóricos podem assumir no contexto do fenômeno do que aqui se denomina fluidez das noções de questões públicas e privadas.

Habermas destaca o papel da cidadania e da democracia enquanto espaços institucionais de articulação da autonomia pública e privada, nos quais os cidadãos passam a ser idealmente concebidos como pessoas dotadas da capacidade discursiva para acionar por meio de questões públicas alguns daqueles assuntos historicamente relegados ao papel quase exclusivo ou, pelo menos, preponderante, da autonomia privada. Esse modelo discursivo ideal permite o reconhecimento do fenômeno procedimental de interpelação recíproca, mediante o qual se tornam possíveis as condições de profunda crítica democrática a quaisquer ingerências sociais e políticas que ameacem a integridade discursiva das autonomias público e privada, no âmbito dos espaços institucionais da democracia e da cidadania.

Por conseguinte, ao menos em tese, os cidadãos e as cidadãs passam a autoreconhecer-se como livres e iguais na tematização intersubjetiva de suas diferenças particulares para o gozo e a proteção de direitos fundamentais soberanamente reconhecidos no processo democrático do uso público da razão. ${ }^{22}$ Como se pode perceber, porém, casos como o da Associação de Mulheres de Juazeiro do Norte devem ser analisados a partir da ótica

\footnotetext{
20 Para uma abordagem que não estabelece, em princípio, distinção entre as estruturas institucionais de circulação de poder e o exercício da violência, $c f$. Arendt (1993).

${ }^{21}$ Para maiores aprofundamentos acerca dessa dimensão privada, $c f$. Benhabib (1992:82-85).

${ }^{22}$ Habermas (2004:65-92). 
segundo a qual nem sempre a conquista legislativa de direitos garante a sua concretização social por meio do exercício individual e coletivo de direitos de liberdade e de igualdade.

Em vez de buscar a pretensão de critérios supostamente "objetivos" para balizar a distinção entre esfera pública e esfera privada, pretende-se enfatizar as possibilidades de compreensão do reconhecimento de direitos individuais e coletivos constitucionalmente garantidos, embora nem sempre assegurados. No contexto dessa discussão, soberana e popular, vale refletir sobre as políticas públicas de radiodifusão que devem, deveriam e deverão nortear o constante processo de realização das prerrogativas fundamentais decorrentes da liberdade e da igualdade.

$\mathrm{Na}$ tentativa de abordar o problema do arquivamento do pedido de autorização da Associação de Mulheres de Juazeiro do Norte (AMUJUN), não se podem perder de vista os potenciais e riscos da feição discursiva que a noção de esfera pública assumiu no pensamento habermasiano. Nesse contexto, denota-se que, para a legitimação minimamente satisfatória da legislação de regência do setor, as políticas públicas de radiodifusão comunitária devem estar continuamente abertas à possibilidade de inclusão de novos atores e de alternativas de realização dos direitos fundamentais constitucionalmente reconhecidos.

Ao propor a reconstrução desses elementos concretos sob a perspectiva da Teoria Discursiva do Direito e da Democracia, observa-se que é minimamente arriscado considerar a existência de uma autonomia pública (soberania popular) ou privada (direitos humanos). Torna-se interessante dimensionar essas autonomias quanto ao papel desempenhado pela cidadania, com base em modelo discursivo de formação e circulação da vontade e do poder político: a esfera pública. ${ }^{23}$

$\mathrm{Na}$ reflexão constitucional, parece interessante a proposta de se compreender a coexistência de múltiplas percepções paradigmáticas acerca da noção de "justo" ou de "bem" para dada comunidade político-jurídica, como a brasileira. De outro lado, no específico campo no qual este ensaio se situa, é fácil perceber que os conceitos de "público" e "privado" podem assumir diversos sentidos concretos de acordo com o uso discursivo que recebam na prática democrática da cidadania.

Sustenta-se, portanto, que essa assertiva pode ser assumida como hipótese de trabalho porque, com base na obra habermasiana, não se pode tratar da definição de políticas públicas de radiodifusão comunitária, sem conceber ampla discussão democrática sobre as demandas de concretização de direitos fundamentais dos cidadãos, cidadãs, e o

${ }^{23}$ Para maiores detalhes acerca da evolução da noção de "esfera pública" no pensamento habermasiano, $c f$. Habermas (1984) e (1992:421-479). 
reconhecimento da construção de identidades sociais coletivas de comunidades e grupos (minoritários ou não). ${ }^{24}$

Nessa roupagem, a cidadania não deve ser compreendida como mera pertinência ao Estado, ou ainda como simples decorrência do exercício de poder econômico. Essa constatação permite afirmar que o caminho intersubjetivo a ser percorrido por cada um dos cidadãos envolve a dimensão indisponível das conquistas do passado, do presente e do futuro acerca de uma reflexão que se coloca aqui, apenas para fins provocativos: qual o papel que a participação política deve assumir na formação de estruturas políticas e jurídicas constitucionalmente mediadas pelo discurso e pela democracia (tais como: na área de implementação de políticas públicas e de realização de direitos fundamentais)?

A partir das tradições morais, jurídicas e políticas existentes no âmbito da tensão entre soberania popular e direitos humanos, Habermas estabelece problematização em torno da noção de cidadania e dos mecanismos de legitimação democrática da atuação estatal balizada pelo direito. ${ }^{25}$ Sob esse enfoque constitucional discursivo, os cidadãos podem ser concebidos, a um só tempo, como destinatários e co-autores da ordem jurídicoconstitucional $^{26}$. Em outros termos, "a idéia democrática de autolegislação não tem opção senão validar-se a si mesma no 'medium' do direito",27.

\section{Possibilidades democráticas e limites à cidadania nas políticas públicas brasileiras de radiodifusão comunitária}

O presente artigo reconhece a importância que a destranscendentalização dos fundamentos do direito moderno ${ }^{28}$ pode desempenhar em um sistema jurídico como o brasileiro, isto é, a ordem jurídica relativamente diferenciada e historicamente adstrita às

\footnotetext{
24 "O paradigma procedimental do direito nutre a expectativa de poder influenciar, não somente a autocompreensão das elites que operam o direito na qualidade de especialistas, mas também a de todos os atingidos. E tal expectativa da teoria do discurso, ao contrário do que se afirma muitas vezes, não visa doutrinação, nem é totalitária. Pois, o novo paradigma submete-se às condições da discussão contínua, cuja formulação é a seguinte: na medida em que ele conseguisse cunhar o horizonte da pré-compreensão de todos os que participam de algum modo e à sua maneira da interpretação da constituição, toda transformação histórica do contexto social poderia ser entendida como um desafio para um reexame da compreensão paradigmática do direito. Esta compreensão, como, aliás, o próprio Estado de direito, conserva um núcleo dogmático, ou seja, a idéia de autonomia, segundo a qual, os homens agem como sujeitos livres na medida em que obedecem às leis que eles mesmos estabeleceram servindo-se de noções adquiridas num processo intersubjetivo. Contudo esta idéia é 'dogmática' num sentido sui generis. Pois, nela se expressa uma tensão entre facticidade e validade, a qual é 'dada' através da estrutura lingüística das formas de vida sócio-culturais, as quais nós, que formamos nossa identidade em seu seio, não podemos eludir." [Habermas (1997b:190 - grifos e realces no original).

${ }^{25}$ Para um desenvolvimento mais adequado da questão, $c f$. Habermas (1997a:113-240).

${ }^{26}$ Habermas (1997a:139).

${ }^{27}$ Habermas (2004c:288).

${ }^{28}$ Para maiores aprofundamentos, $c f$. Habermas (2002).

PRISMAS: Dir., Pol.Pub. e Mundial., Brasília, v.3, n, 2, p. 256-277, jul/dez.2006 
repercussões democráticas decorrentes do processo de aprendizado haurido nos sucessivos paradigmas de Estado de Direito ${ }^{29}$. Por esse motivo, não se pode deixar de reconhecer a existência contemporânea de coesão interna entre cidadania, Estado, Democracia, Constituição e Direito:o Estado Democrático de Direito. ${ }^{30}$

Nesse contexto, tanto as liberdades subjetivas fundamentais (ou morais) de exercício de ações sociais permitidas, devidas ou proibidas pelo direito (autonomia privada), quanto às liberdades comunicativas (ou políticas) dos cidadãos para a construção soberana da democracia em respeito à pluralidade e às minorias (autonomia pública) destinam-se a esclarecer as condições para a produção legítima com base em um direito constitucionalmente positivado $^{31}$. Isto é, para analisar a legitimidade racional do direito em determinada sociedade, deve-se admitir a autonomia privada como pressuposto da autonomia pública e viceversa.Entretanto, deve-se alertar que, ao levarem- se a sério as pretensões da teoria habermasiana, esse postulado da co-originariedade (ou da eqüiprimordialidade), por si só, é insuficiente. Isso ocorre porque tal premissa não garante a feição de legitimidade discursiva do direito.

Apesar da sofisticação dessa intuição habermasiana, caberia questionar: qual é a utilidade de depositar as esperanças emancipatórias da democracia e da cidadania no direito? Afinal, quais seriam os limites da idealização normativo-discursiva da esfera pública e da sociedade civil?

A esse respeito, é pertinente mencionar algumas das principais reflexões e críticas realizadas à ênfase que a visão discursivo-normativa apresentada por Habermas impõe quanto à noção de esfera pública.

Em crítica a esse modelo normativo da sociedade, Thomas McCarthy ${ }^{32}$ apresenta problemas decorrentes da noção habermasiana de "esfera pública". Para o autor, em função das sobrecarregadas pressuposições discursivas idealizantes que são impostas a cada um dos participantes potencialmente envolvidos, antes mesmo de projetar essa imagem sociológica do direito, seria interessante considerar que nem sempre todos os partícipes possuem as mesmas oportunidades jurídico-discursivas para expressar, de modo radicalmente democrático, suas opiniões, posições e desejos, a partir da mera idealização de uma espécie de "reciprocidade igualitária" de influências entre os atores sociais.

\footnotetext{
${ }^{29}$ Carvalho Netto (1998:233-250) e (2001:11-20).

${ }^{30}$ Habermas (2004b:293-305).

${ }^{31}$ Habermas (1997a:185).

32 Para maiores detalhes, $c f$. McCarthy (1992:50-72).

PRISMAS: Dir., Pol.Pub. e Mundial., Brasília, v.3, n, 2, p. 256-277, jul/dez.2006
} 
A esse respeito, Habermas sustenta que não se pode adotar a postura ingênua de que a satisfação procedimental de condições ético discursivas desconsidera os múltiplos fatores jurídicos "materiais" e "formais" que informariam a realidade social. Nas palavras do autor:

Os direitos só se tornam socialmente eficazes, quando os atingidos são suficientemente informados e capazes de atualizar, em casos específicos, a proteção do direito garantida através de direitos fundamentais de justiça. A competência de mobilizar o direito depende, em geral, do grau de escolaridade, da procedência social e de outras variáveis (tais como sexo, idade, experiência em processos, tipo de relação social envolvida no conflito, etc.). E a utilização do direito materializado levanta enormes barreiras, exigindo do leigo que decomponha seus problemas cotidianos (do trabalho, lazer e consumo, moradia, doença, etc.) em construções jurídicas muito especializadas, abstraídas dos contextos da experiência do mundo da vida. Daí a necessidade de uma política compensatória de proteção jurídica, capaz de fortalecer o conhecimento do direito, a capacidade de percepção, de articulação e de imposição por partes dos clientes carentes de proteção. $\mathrm{O}$ contrapoder dos interesses sociais pode ser reforçado através da coletivização da imposição do direito, isto é, através de medidas convencionais, tais como seguro de proteção jurídica, assunção dos custos dos processos etc. ${ }^{33}$

A reconstrução habermasiana da sociedade civil, por outro lado, é confessadamente influenciada pela obra de Jean Cohen e Andrew Arato. Nessa formulação, esses autores propõem uma relação mediatizada democraticamente segundo a qual a sociedade civil é entendida como instância de socialização diferente do Estado e da economia. Nesse contexto, torna-se possível que, em situações excepcionais, os atores envolvidos invoquem a arena da discussão pública para a tematização de questões não resolvidas ou insuficientemente problematizadas. ${ }^{34}$

A respeito dos limites da idealização normativa na noção habermasiana de sociedade civil, é pertinente mencionar as preocupações de Nancy Fraser, tanto na formulação original de Mudança Estrutural (1961), quanto nos posteriores prolongamentos dos novos elementos discursivo-normativos elaborados por Habermas em sua concepção pós-burguesa de sociedade civil. ${ }^{35}$ Relativamente à primeira concepção, a autora repara nos riscos de adotar generalizações históricas e sociais da sociedade civil burguesa (intimamente atrelada às relações capitalistas do ideário burguês) para projetar, inadequadamente, o fenômeno da "sociedade civil" nos âmbito de sociedades complexas e pluralistas. Ademais, essa suposta

\footnotetext{
${ }^{33}$ Habermas (1997b:149).

${ }^{34}$ Cohen e Arato (2000:10).

${ }^{35}$ Para maiores aprofundamentos, $c f$. Fraser (1992:109-142).

PRISMAS: Dir., Pol.Pub. e Mundial., Brasília, v.3, n, 2, p. 256-277, jul/dez.2006
} 
distorção poderia comprometer os postulados democráticos de "inclusão social", mesmo sob as reformulações normativas empreendidas por Habermas.

Nesse diapasão, Fraser apresenta as dificuldades das condições discursivas de "como" os atores da "sociedade civil" deveriam articular- se para canalizar aspectos de seus domínios privados para a infra-estrutura comunicativa de uma esfera pública política projetada indistintamente a todos os "supostos" cidadãos. Quanto a isso, deve-se esclarecer que, de fato, Habermas não condiciona a possibilidade de vocalização ou tematização a grupos específicos (por exemplo, determinada associação de mulheres). Ou seja, em princípio, não é necessário que os atores pertençam a determinados grupos de interesse, coletividades associativas, sindicatos, partidos ou quaisquer organizações específicas no interior da "sociedade civil" porque todos esses sujeitos, cidadãos ou cidadãs, compartilham intersubjetivamente uma tradição cultural comum.

Para esse enfoque da Teoria Discursiva, a possibilidade de problematização de questões relevantes para toda a sociedade é condição suficiente desde que sejam atendidos os imperativos discursivo-procedimentais de generalização de pretensões normativas. Destarte, a "sociedade civil" somente poderá ser sustentáculo dos processos de formação de opinião e vontade política à proporção que se mantenha afastada da excessiva burocratização e formalização, de tal modo que as fronteiras entre os atores sociais sejam cada vez mais permeáveis e fluidas.

Nesse particular, não é difícil reconhecer os limites à emancipação política que o atual modelo de autorização das rádios comunitárias apresenta. No âmbito de políticas públicas que têm sido historicamente apropriadas e vocalizadas em prol de interesses partidários e religiosos, notam-se os problemas existentes na constante privatização da esfera pública, a qual tem sido implementada por meio de fortes indícios concentração econômica da radiodifusão e da insustentável burocracia do aparato estatal destinado a exercer o controle normativo dessas atividades. Assim, embora o tema da concentração econômica e da burocracia estatal demande estudos mais detalhados acerca do efetivo comprometimento da participação de determinados grupos sociais nas políticas públicas desse setor ${ }^{36}$, é válida a preocupação habermasiana segundo a qual a tentativa de prescrever as performances

\footnotetext{
${ }^{36}$ Nesse sentido, Lopes (2005) indica a incompletude de dados e carência de estudos e levantamentos estatísticos mais detalhados e aprofundados para a identificação dos mecanismos de concentração nos mercados nacional e internacional e da correspondente dificuldade do aparato Estado Brasileiro para lidar, de modo eficiente e legítimo, com as políticas públicas do setor de radiodifusão comunitária. 
discursivas dos atores sociais pode comprometer as possibilidades de participação democrática na "esfera pública". 37

De outro lado, afora as sofisticações discursivas proporcionadas pelas noções de "esfera pública" e "esfera privada", não se podem desconsiderar os riscos de que um fenômeno na sociedade burguesa do século XVIII seja projetado por meio de universalizações históricas ou espaciais irrestritas. Nesse caso, a apropriação indevida da obra de Jürgen Habermas pode assumir o equívoco de tentar retratar imagens distorcidas do público e do privado no tempo e no espaço. Como alerta Harold Mah:

A espacialização da esfera pública feita por historiadores negligencia, de fato, precisamente esse aspecto da esfera pública que mais tem dado trabalho aos observadores históricos: nomeadamente, o modo como a esfera pública se constrói enquanto uma entidade unitária e, ao fazer isso, misteriosamente, muda de forma. Ela deixa de ser imaginada como espaço racional de grupos sociais em conflito e passa a ser representada como uma esfera singular, unificada, um sujeito massificado. O que muitos historiadores vêem atualmente como o propósito da esfera pública - prover espaço para a livre expressão de identidades e interesses sociais conflitantes - acaba por se tornar somente uma condição preliminar, que, de acordo com a lógica da esfera pública, deve ser adicionada a uma série de transformações que fundem as pessoas em um sujeito unitário, coletivo, não mais uma "esfera pública" mas, agora, o "público" 38 .

Apesar dessas ressalvas, não se pode negar o potencial que a perspectiva da Teoria Discursiva proporciona. Para Seyla Benhabib ${ }^{39}$, embora remanesçam possibilidades indesejáveis de distorção de imagens sociológicas no tempo e no espaço, a pertinência da abordagem habermasiana confirma-se porque a questão da legitimação democrática assume papel central nas sociedades do capitalismo avançado.

A pesar de reconhecer esses avanços apontados por Habermas com relação à formação de um modelo histórico e institucional de oposição política ao Antigo Regime, Joan

\footnotetext{
${ }^{37}$ Para desdobramentos críticos posteriores a essas (re)visões habermasianas, sob a perspectiva de substituição de políticas redistributivas por iniciativas públicas de inclusão pelo reconhecimento diferenças de "gênero" e de "raça" no âmbito da sociedade civil, $c f$. Fraser (2001).

38 Tradução livre da seguinte afirmação de Mah (2000:155): “The historian's spatialization of the public sphere neglects, in fact, precisely that aspect of the public sphere that has most troubled its historical observers: namely, how the public sphere constructs itself as a unitary entity and in doing so mysteriously changes form. No longer an imagined rational space of disagreeing social groups, it comes to be represented as a single, unified being, a mass subject. What many historians currently see as the purpose of the public sphere - to provide a space for the free expression of disagreeing social identities and interests - turns out to be only a preliminary condition, which, according to the logic of the public sphere, is to be surmounted in a series of transformations that fuse persons into a unitary, collective subject, no longer a 'public sphere', but now the 'public'.".

39 Nesse ponto, Benhabib (1992) analisa as três principais correntes do pensamento político ocidental acerca da noção de esfera pública e aponta as vantagens da concepção discursiva habermasiana em detrimento dos outros modelos: i) o legalista ou liberal de Bruce Ackerman; e ii) o republicanista ou agonístico de Hannah Arendt. 
Landes evidencia a permanência histórica de estruturas patriarcalistas de exclusão da outra ${ }^{40}$. Logo, a primeira premissa a ser desmistificada consiste no fato de que a necessidade de inclusão generalizada das mulheres não pode ser reduzida a uma experiência da sociedade brasileira atual. Segundo Robert Darnton, suas origens remontam à esfera pública política e literária da França do século XVIII: "Os philosophes advogavam uma visão instrumentalista da razão, o que levou ao desastre ecológico, e uma visão masculina da cidadania, o que relegou as mulheres à esfera privada." ${ }^{, 41}$

Assim, a descoberta dessas evidências históricas deve ser compreendida no sentido de que não é mais possível reproduzir, de modo ingênuo, as respostas oferecidas pela obra Mudança Estrutural da Esfera Pública (1984). Permanecem, em aberto, porém, algumas perguntas formuladas, com base no pensamento de Habermas, acerca das possibilidades de sua aplicação em contextos como o brasileiro - historicamente marcado pelo autoritarismo ${ }^{42} \mathrm{e}$ pela exclusão social ${ }^{43}$.

Essa percepção indica uma necessidade, cada vez mais presente, de redefinir os subsídios teóricos e práticos da democracia e do direito no Brasil. Nesse cenário, subsistem as seguintes perplexidades, as quais ficam, aqui, apenas a título provocativo: I) Como o constitucionalismo brasileiro pode harmonizar os desdobramentos tecnológicos da mídia com a multiplicação dos paradoxos de inclusão e exclusão de minorias (gênero, raça, credo etc.) ${ }^{44}$ ?; II) Em contextos sociais caracterizados pela pluralidade e pela exclusão, de que modo se poderiam reconhecer essas diferenças, sem negar a identidade constitucional de determinada comunidade jurídico-política?; III) Afinal, quem é o povo brasileiro? Quem (ainda) não o é?

\footnotetext{
${ }^{40}$ Nesse particular, Joan Landes destaca as barreiras de participação política feminina na "nova" esfera pública burguesa e propõe o eixo do feminismo como uma perspectiva para analisar o tema do acesso feminino aos textos que circulavam na Europa do Século XVIII. Ademais, Landes invoca o fato de que alguns dos salões eram organizados, inclusive, por mulheres e chama a atenção para a existência das lojas maçônicas femininas como evidências históricas que nos levam a questionar sobre o "papel natural" da mulher nos cafés. Daí as dificuldades decorrentes de uma identificação do "público" com masculino e do "privado" com feminino. Para maiores aprofundamentos, $c f$. La Vopa (1992:114/115).

${ }^{41}$ Darnton (2005:33).

${ }^{42}$ Carvalho (2003 e 1987).

${ }^{43}$ Müller(2005).

${ }^{44}$ Para estudos informativos acerca desse tema, no âmbito da radiodifusão comunitária no Brasil, vale mencionar novamente as obras de Cristiano Aguiar Lopes (2005) e Célia Stadnick (1991), os quais apontam, respectivamente: i) as possibilidades de inclusão no contexto dos entraves burocráticos; e ii) o surgimento de práticas renovadas de favorecimento político (como o coronelismo eletrônico, por exemplo). 
Em vez de oferecer respostas, este artigo parte do princípio jurídico-discursivo da democracia constitucional ${ }^{45}$, o qual sugere que os âmbitos público e privado somente podem ser compreendidos como pressuposições institucionalizadas em contextos normativos concorrentes acerca do adequado exercício da cidadania. É possível inferir, portanto, que as conformações discursivas do direito e da democracia devem proporcionar a concorrência entre autonomia pública e privada, de tal modo que seja possível verificar a permanência da tensão democrática que permita a distinção entre o papel que o público e o privado podem exercer em casos como o enunciado no início deste trabalho.

Assume-se como válida, por conseguinte, a sugestão habermasiana de que ainda é possível (re)pensar a divisão de poderes do Estado de Direito ${ }^{46}$ em um contexto no qual a distinção entre público e privado não pode ser separada da análise de legitimidade das normas jurídicas ${ }^{47}$. Em outro nível, tornar-se pertinente buscar subsídios para se discernir a atuação do público, do privado e do estatal no caso concreto da AMUJUN.

\section{Análise jurídico-constitucional do caso AMUJUN: a pluralidade contra a diferença?}

Embora essas tarefas não estejam, nem de longe, solucionadas por essa breve problematização apresentada, é válido lançar algumas considerações sobre o processo de implementação administrativa de políticas públicas e direitos fundamentais no modelo brasileiro de autorização das rádios comunitárias.

$\mathrm{Na}$ hipótese da negativa de autorização para a exploração, pela AMUJUN, do serviço de radiodifusão comunitária, o Ministério das Comunicações (MINICOM) invocou o inciso I, do artigo 4을 da Lei no 9.612/1998. Esse dispositivo normativo estabelece que as emissoras devem atender, em sua programação, ao "princípio" da "não discriminação de raça, religião, sexo, preferências sexuais, convicções político-ideológico-partidárias e condição social nas relações comunitárias”. Assim, caberia indagar: quais são as repercussões jurídicoconstitucionais do arquivamento do pedido de autorização da AMUJUN? É possível levar a

${ }^{45}$ A Teoria Discursiva do Direito e da Democracia estabelece como condições de validade da democracia: i) o Princípio D [Habermas (1997a:142)]; e ii) a forma jurídica comunicativa proporcionada institucionalmente pelo medium do direito [Habermas, (1997a:165)].

46 Para maiores aprofundamentos acerca da proposta habermasiana de divisão discursiva dos poderes, $c f$. Habermas (1997a:211-240).

${ }^{47}$ Habermas (1997a:169-170) preconiza: "Para que o entrelaçamento jurídico entre autonomia pública e privada seja duradouro, é necessário que o processo da juridificação não se limite às liberdades subjetivas de ação das pessoas privadas e às liberdades comunicativas dos cidadãos. Ele deve estender-se, simultaneamente, ao poder político - já pressuposto com o medium do direito - do qual depende a obrigatoriedade fática da normatização e da implantação do direito. Da constituição co-originária e da interligação conceitual entre direito e poder político resulta uma ulterior necessidade de legitimação, ou seja, a de canalizar o poder político executivo, de organização e de sanção, pelas vias do direito. Esta é a idéia do Estado de direito.” 
sério o argumento de que, em princípio, a outorga da autorização daria vazão à promoção de “discriminação sexual”?

Ao que parece, no caso concreto em questão, houve uma certa inadequação no discurso jurídico expendido pelo poder executivo brasileiro. Observa-se que as finalidades legalmente instituídas para o Serviço de Radiodifusão Comunitária $(\mathrm{SRC})^{48}$ foram simplesmente negligenciadas. Nesse sentido, a mera transcrição de alguns dispositivos da mesma lei ${ }^{49}$ já poderia dar-nos uma dimensão das perdas quanto à utilidade pública que a livre difusão de idéias e elementos culturais pode proporcionar para o exercício da cidadania. Ademais, segundo as condições de idealização discursivo-normativa que a noção de esfera pública assumiu no pensamento habermasiano, não é necessário muito esforço argumentativo para indicar os problemas democráticos que esse tipo de interpretação do direito pode ocasionar.

Denota-se, em primeiro lugar, total desrespeito quanto às possibilidades de articulação normativa da autonomia (pública e privada) da AMUJUN e de cada uma das mulheres envolvidas na tentativa de promover uma radiodifusão direcionada a um importante fator para aquela comunidade. São inegáveis as contribuições para a cidadania e a democracia que a tematização de questões, como violência doméstica, por exemplo, poderiam oferecer para a construção de uma identidade do papel a ser exercido pela autonomia da mulher.

Como se não bastasse (e esta questão é crucial em termos de uma visão constitucional), a "fundamentação jurídica" empregada para a negativa de autorização desconsiderou, por completo, a observância, expressa no texto da Constituição Federal, do "princípio da complementaridade dos sistemas privado, público e estatal” (CF, art. 223). ${ }^{50}$ Pode-se afirmar, portanto, que a Administração implementou uma argumentação do direito que, ao aferrar-se a uma superficial leitura da legalidade dos atos administrativos de autorização, acabou por utilizar, ilegítima e paradoxalmente, a pluralidade contra a possibilidade da diferença.

\footnotetext{
${ }^{48} \mathrm{O}$ art. 1ํㅡㄹ da Lei no 9.612/1998 estipula que a denominação técnica "Serviço de Radiodifusão Comunitária" (SRC) corresponde a: "a radiodifusão sonora, em freqüência modulada, operada em baixa potência e cobertura restrita, outorgada a fundações e associações comunitárias, sem fins lucrativos, com sede na localidade de prestação do serviço."

${ }^{49}$ Segundo dispõe o art. 3ㅇ da Lei no 9.612/1998: "O Serviço de Radiodifusão Comunitária tem por finalidade o atendimento à comunidade beneficiada, com vistas a: I - dar oportunidade à difusão de idéias, elementos de cultura, tradições e hábitos sociais da comunidade; II - oferecer mecanismos à formação e integração da comunidade, estimulando o lazer, a cultura e o convívio social; III - prestar serviços de utilidade pública, integrando-se aos serviços de defesa civil, sempre que necessário; (...) V- permitir a capacitação dos cidadãos no exercício do direito de expressão da forma mais acessível possível."

$50 \mathrm{O}$ art. 223, da Constituição Federal estabelece que: "Compete ao Poder Executivo outorgar e renovar concessão, permissão e autorização para o serviço de radiodifusão sonora e de sons e imagens, observado o princípio da complementaridade dos sistemas privado, público e estatal."
} 
Conforme prenunciado neste ensaio, o exemplo concreto da negativa de autorização à AMUJUN oferece subsídios para que a questão da diferença seja articulada com as possibilidades discursivas da noção de esfera pública no pensamento de Jürgen Habermas. As críticas que enfatizam a questão do gênero (em especial, as formuladas nas obras de Seyla Benhabib e Nancy Fraser ${ }^{51}$ ), tentam colocar em cheque a validade normativa dessa noção habermasiana quanto às possibilidades de inclusão da mulher no modelo discursivo ideal.

Essa perspectiva crítica pretende alcançar possibilidades de inclusão da outra em detrimento das várias exclusões em que a esfera pública burguesa estaria assentada, as quais não seriam meramente contingentes, mas historicamente constitutivas. Por conseguinte, tais intelectuais do "movimento feminista" ressaltam que, se a condição de ser homem, branco, letrado e proprietário fosse, de alguma maneira, constitutiva para o acesso ao público, a tese de Habermas sobre os ideais utópicos modernos não realizados ver-se-ia seriamente afetada. Destarte, se não se pode esperar que os ideais igualitários pressupostos nesse domínio do público funcionem como corretivos dos mecanismos de exclusão, é necessário propor compreensão que permita, efetivamente, a emancipação e a autonomia (pública e privada) das mulheres (também) enquanto autoras e destinatárias das políticas públicas de radiodifusão comunitária.

Uma vez que o ideal discursivo do uso público da razão supõe indivíduos livres que se reconheçam reciprocamente como iguais em que rege a "lei do melhor argumento", sem importar a identidade dos ou das falantes denota-se que esse modelo discursivo pode apresentar baixa porosidade para o reconhecimento de diferenças. Veja-se, nesse sentido, o caso sob análise, no qual a pluralidade discursiva foi articulada em face da própria pluralidade (ou seja, contrariamente às possibilidades democráticas do reconhecimento da diferença $d a$ diferente).

Assim, surge o problema de investigar se a identificação ideológica entre bourgeois e homme (na qual a esfera pública burguesa se originou) não favorecera a construção da identidade "masculina" em detrimento das demais. É pertinente indagar: será que o "masculino" passou a assumir um lugar de centralidade no debate público, neutralizando as demais identidades possíveis? Isto é, de que maneira esse fenômeno impede que a diferença "feminina" seja devidamente tematizada? E mais, considerados esses limites, qual é o papel que a mulher pode desempenhar na política de radiodifusão comunitária no

\footnotetext{
${ }^{51}$ A esse respeito, $c f$. Benhabib (1996 e 1992) e Fraser (2001 e 1992).
} 
Brasil? Será que o exercício da tematização da diferença de "gênero" deve ser lido como “discriminação sexual”?

A esse respeito, embora Habermas nunca tenha negado que a esfera pública burguesa funcionou, desde seu início, com base na dominação e na exclusão da maioria dos atores sociais, o seu modelo normativo ainda insiste em formular saídas discursivas e argumentativas que permitam a autocorreção, mediada pelo direito, para lidar com os riscos de homogeneização e de negativa da diferença. Nesse particular, na obra $A$ inclusão do outro, o autor afirma que: "inserção significa que tal ordem política se mantém aberta para equiparar os discriminados e para incluir os marginalizados, sem confiná-los na comunidade homogênea de um povo., ${ }^{52}$.

De acordo com o modelo de razão comunicativa, portanto, as críticas daqueles e daquelas que têm sido sistemática e historicamente excluídos e excluídas das possibilidades efetivas do uso público da razão só poderiam ser articuladas pressupondo as normas discursivas ideais da esfera pública. Apesar dos méritos do esforço empreendido por Habermas $^{53}$ no sentido de que ainda é possível pensar as condições de realização da emancipação política na modernidade, caberia indagar acerca de onde estariam os "lugares seguros" contra os arbítrios da exclusão da mulher e das autoridades "masculinas" tradicionalmente impostas na esfera pública.

Em resposta a esse tipo de problemática, Miroslav Milovic apresenta interessante sugestão: "Eu teria muitas dúvidas sobre a casa de um habermasiano, porque tudo pode acontecer com a nossa vida até encontrarmos uma solução discursiva." ${ }^{, 54}$

Em conclusão, casos como o da AMUJUN, em que a pluralidade é utilizada, de modo paradoxal, contra o reconhecimento discursivo da(s) diferença(s) de gênero, comprometem as possibilidades jurídicas de inclusão da outra. Perde-se, de um lado, o reconhecimento da mulher como titular de direitos de liberdade e igualdade invocáveis na esfera pública e, de outro, a democratização do acesso ao planejamento de políticas públicas de radiodifusão permanece como uma tarefa adiada - pendente de realização e vocalização pelos cidadãos, grupos e comunidades excluídos.

Como se observa, não há solução simples para esse problema. A complexidade das políticas públicas destinadas às rádios comunitárias pode envolver, além da luta e conquista de direitos de liberdade de expressão e igualdade de gêneros, a construção

\footnotetext{
${ }^{52}$ Habermas (2002a:154).

${ }^{53}$ Para maiores aprofundamentos, $c f$. Habermas (2004a; 2004b; 2004c; 2003; 2002; 1997a; 1997b; e 1992).

${ }^{54}$ Milovic (2004:119).

PRISMAS: Dir., Pol.Pub. e Mundial., Brasília, v.3, n, 2, p. 256-277, jul/dez.2006
} 
democrática da cidadania e a emancipação política de identidades sociais coletivas mesmo em contextos autoritários $^{55}$ e de exclusão ${ }^{56}$ como o brasileiro. Esse tipo de experiência indica a necessidade, cada vez mais presente, de redefinir os subsídios teóricos e práticos da democracia e do direito (consideradas as possibilidades e limites às alternativas de emancipação na "Casa de Habermas").

Artigo recebido em agosto de 2006

Aceito em setembro de 2006

\section{Referências}

Arendt, Hannah. A condição humana. 6. ed. Rio de Janeiro: Forense Universitária, 1993.

Benhabib, Seyla (Ed.). Democracy and difference: Contesting the boundaries of the political. New Jersey: Princeton University Press, 1996.

. Models of Public Space: Hannah Arendt, the Liberal Tradition, and Jürgen Habermas. In: Calhoun, Craig (Ed.), 1992. pp. 73-98.

Calhoun, Craig (Ed.). Habermas and the public sphere. (Studies in contemporary German social thought). Massachussets Institute of Technology, 1992.

Carvalho, José Murilo. Cidadania no Brasil: o longo caminho. $4^{\text {a }}$ Ed. Rio de Janeiro: Civilização Brasileira, 2003.

Os bestializados: $O$ Rio de Janeiro e a República que não foi. $3^{\mathrm{a}} \mathrm{Ed} .12^{\mathrm{a}}$ Reimpressão. Rio de Janeiro: Companhia das Letras, 1987, pp 66-160.

Cohen, Jean L. e Arato, Andrew. Sociedad Civil y Teoría Política. Tradución de Roberto Reyes Mazzoni. Fondo de Cultura Econômica: México, 2000, pp. 395-681.

Darnton, Robert. Os dentes falsos de George Washington - Um guia não convencional para o século XVIII. Tradução de José Geraldo Couto. São Paulo: Companhia das Letras, 2005, pp. 17-90.

Fraser, Nancy. Da redistribuição ao reconhecimento? dilemas da justiça na era póssocialista. In: SOUZA, Jessé (org) Democracia Hoje: novos desafios para a teoria democrática contemporânea. Brasília: Editora da UnB, 2001.

Rethinking the Public Sphere: A contribution to the critique of actually xxisting democracy. In: Calhoun, Craig (Ed.), 1992. pp. 109-142.

\footnotetext{
${ }^{55}$ Carvalho (2003 e 1987).

${ }^{56}$ MÜLLER (2005).

PRISMAS: Dir., Pol.Pub. e Mundial., Brasília, v.3, n, 2, p. 256-277, jul/dez.2006
} 
Habermas, Jürgen. A Ética da discussão e a questão da verdade. Tradução de Marcelo Brandão Cipolla. Organização e introdução de Patrick Savidan. São Paulo: Martins Fontes, 2004a.

. A inclusão do outro - estudos de teoria política. Tradução de George Sperber e Paulo Astor Soethe. São Paulo: Loyola, 2004b.

. Verdade e justificação: estudos filosóficos. Tradução de Milton Camargo Mota. São Paulo: Loyola, 2004c.

Era das Transições. Tradução de Flávio Beno Siebeneichler. Rio de Janeiro:

Tempo Brasileiro, 2003.

Agir comunicativo e razão destranscendentalizada. Tradução de Lucia Aragão. Revisão de Daniel Camarinha da Silva. Rio de Janeiro: Tempo Brasileiro, 2002.

Direito e Democracia: entre facticidade e validade I. Tradução de Flávio Beno Siebeneichler. Rio de janeiro: Tempo Brasileiro, 1997a.

Direito e Democracia: entre facticidade e validade II. Tradução de Flávio Beno Siebeneichler. Rio de janeiro: Tempo Brasileiro, $1997 \mathrm{~b}$.

Further reflections on the Public Sphere e Concluding Remarks. Translated by Thomas Burger In: Craig, Calhoun (Ed.), 1992. pp. 421-479.

Mudança Estrutural da Esfera Pública: investigações quanto a uma categoria da sociedade burguesa. Tradução de Flávio R. Kothe. Rio de Janeiro: Tempo Brasileiro, 1984.

La Vopa, Anthony J. Conceiving a Public: Ideas and Society in the Eighteenth-Century Europe. In: The Journal of Modern History. Março: 1992; 64, 1. Academic Research Library. pp. 79-116.

Lopes, Cristiano Aguiar. Política pública de radiodifusão comunitária no Brasil: Exclusão como estratégia de contra-reforma. Dissertação de mestrado apresentada para a obtenção do título de Mestre na Faculdade de Comunicação da Universidade de Brasília. Orientador: Professor Dr. Murilo César Ramos. Abril, 2005.

Mah, Harold. Phantasies of the Public Sphere: Rethinking the Habermas of Historians. In: The Journal of Modern History; Mar. 2000, 72, 1; Academic Research Library, pp. 153182.

McCarthy, Thomas. Practical Discourse: on relation of morality on Politics. In: Craig, Calhoun (Ed.), 1992. pp. 50-72.

Milovic, Miroslav. Comunidade da Diferença. Rio de Janeiro: Relume Dumará; Ijuí, RS: Unijuí, 2004.

Müller, Friedrich. Democracia e Exclusão Social em Face da Globalização. Revista Jurídica Virtual / Presidência da República. Vol. 7, n ㅇ 72 (maio/2005). Brasília. Disponível no sítio eletrônico da Presidência da república (último acesso em 14/06/2005): http://www.presidencia.gov.br/ccivil 03/revista/RevistaJuridica. 
Stadnick, Célia A. A hipótese do fenômeno do Coronelismo Eletrônico e as ligações dos parlamentares federais e governadores com os meios de comunicação de massa no Brasil. Porto Alegre, Pontifícia Universidade Católica do Rio Grande do Sul (PUC-RS), 1991. Mimeo. 


\section{Resumo}

Este artigo enfoca alguns dos dilemas do controle normativo das políticas públicas de radiodifusão comunitária no Brasil, que consiste em uma área caracterizada pela exclusão da participação dos cidadãos por meio de interferências da burocracia do Estado e da concentração do mercado. Com base na Teoria da Democracia e do Direito de Jürgen Habermas, busca-se identificar as repercussões jurídicas do modelo de outorga de autorizações para a exploração de rádios comunitárias. Esta investigação articula questões constitucionais de aplicação da Lei 9.612/1998 ao caso da Associação das Mulheres de Juazeiro do Norte (AMUJUN) Com base nessa situação, apresentam-se elementos sociológicos, jurídicos e historiográficos de revisão da noção habermasiana da esfera pública quanto às possibilidades e aos limites da emancipação política da mulher na sociedade brasileira. Por fim, este ensaio reconhece que a questão das políticas públicas destinadas às rádios comunitárias pode envolver, além da luta e da conquista de direitos de liberdade de expressão e igualdade de gêneros, a construção democrática da cidadania e a emancipação política de identidades sociais coletivas.

Palavras-chave: Políticas Públicas. Radiodifusão Comunitária. Cidadania.
The focus of this article falls on some of the dilemmas that involve normative control of Brazilian public policies in community radio broadcasting. This type of broadcasting is marked by a lack of citizen participation due to interferences of State bureaucracy and market concentration. Based upon Jürgen Habermas' Theory on Democracy and Law, this essay attempts to identify the legal repercussions of Brazil's authorization model for the usage of community radio broadcast stations. This investigation addresses constitutional issues related to the enforcement of Act 9612/1998 to the case of The Association of Women of Juazeiro do Norte (AMUJUN). In view of this fact, the essay attempts to identify sociological, legal and historical elements to revise the habermasian idea of public sphere, as to the possibilities and limits of political emancipation of women in Brazilian society. In conclusion, the study recognizes that the issue of political policies aimed at community radio broadcast stations may involve not only the struggle and conquest of freedom of expression and equal respect of gender differences, but also a democratic construction of citizenship and a political emancipation of social collective identities.

Key Words: Public Policies; Community Radio Broadcasting and Citizenship. 